\title{
Kontribusi Kelengkapan Pengisian Formulir Rekonsiliasi Obat terhadap Penggunaan Obat Rasional pada Pasien Rawat Inap di RSU X Bekasi
}

\section{Contributions to the Completeness of Filling Out the Drug Reconciliation Form Against Rational Medicine Use in Inpatients at the General Hospital X Bekasi}

\author{
Kurniatul Hasanah $^{1^{*}}$, Retnosari Andrajati ${ }^{1}$, Sudibyo Supardi ${ }^{2}$ \\ ${ }^{1}$ Fakultas Farmasi Universitas Indonesia, Depok, Indonesia \\ ${ }^{2}$ Puslitbang Sumber Daya dan Pelayanan Kesehatan, Jakarta, Indonesia \\ *Email : niasai25@gmail.com
}

\begin{abstract}
Abstrak
Rekonsiliasi obat pada pasien rawat inap diperlukan untuk mendapatkan terapi pengobatan yang rasional. Tujuan penelitian ini adalah menilai hubungan antara kelengkapan pengisian formulir rekonsiliasi obat dan penggunaan obat rasional pada pasien rawat inap di RSU X Bekasi. Rancangan penelitian menggunakan studi komparatif potong lintang untuk membandingkan antara 56 formulir rekonsiliasi obat yang diisi lengkap dan 133 formulir yang diisi tidak lengkap. Pengambilan sampel dilakukan secara total sampling. Populasi penelitian adalah semua (466) formulir rekonsiliasi obat pada pasien rawat inap bulan November 2015 sampai dengan April 2016 di RSU X Bekasi. Sampel adalah formulir rekonsiliasi obat yang telah diisi, didapat sebesar 189 formulir $(40,6 \%)$ dari semua (466) formulir rekonsiliasi obat. Analisis data menggunakan uji Chi-square. Hasil penelitian menunjukkan persentase terbesar pengisian formulir rekonsiliasi obat tidak lengkap $(70,4 \%)$, dilakukan oleh apoteker $(56,1 \%)$ dan tidak ada tanda tangan dokter $(63,5 \%)$. Persentase penggunaan obat rasional sebesar 7,9\%, dengan rincian: tepat diagnosis $53,4 \%$, tepat indikasi $53,4 \%$, tepat pemilihan obat $33,9 \%$, tepat dosis $8,5 \%$, tepat cara pemberian $37,6 \%$, tepat waktu pemberian $13,8 \%$ dan tepat lama pemberian $14,8 \%$. Tidak ada hubungan bermakna antara kelengkapan pengisian formulir rekonsiliasi obat, jenis tenaga kesehatan, ada/ tidaknya tanda tangan dokter dan penggunaan obat rasional pada pasien rawat inap $(\mathrm{p}>0,05)$. Tidak ada hubungan yang bermakna antara kelengkapan pengisian formulir rekonsiliasi obat dan penggunaan obat rasional pada pasien rawat inap di RSU X Bekasi $(p>0,05)$.
\end{abstract}

Kata kunci: Formulir rekonsiliasi; Penggunaan obat rasional; Pasien rawat inap

\begin{abstract}
Drug reconciliation is needed to get rational treatment therapy. The purpose of this study was to analyze the relationship between the completeness of filling out the form of drug reconciliation and rational drug use at Bekasi X Hospital. The study design used a cross-sectional comparative study to compare between 56 completed drug reconciliation forms and 133 incomplete drug reconciliation forms. Sampling is done in total sampling. The research sample that fulfilled the inclusion criteria was 189 forms (40.6\%) of all (466) drug reconciliation forms in November 2015-end April 2016 at X Hospital Bekasi. Data was analyzed using Chi-square test. The results showed that the largest percentage of filling out drug reconciliation forms was incomplete (70.4\%), carried out by the pharmacist (56.1\%) and not signed by a doctor (63.5\%). Percentage of rational drug use by $7.9 \%$, with details: correct diagnosis $53.4 \%$, correct indication $53.4 \%$, correct selection of medicine $33.9 \%$, correct dosage $8.5 \%$, exactly how to administer $37.6 \%$, on time giving $13.8 \%$ and correct time giving $14.8 \%$. There is no significant relationship between the completeness of filling out the drug reconciliation form, the types of health workers, the presencelabsence of a doctor's signature and rational drug use in inpatients ( $p>$ $0.05)$.Tthere is no significant relationship between the completeness of filling out the reconciliation form and rational drug use in inpatients at Bekasi X Hospital ( $p>0.05)$.
\end{abstract}

Key words: Reconciliation form; Rational medication use; Inpatient 


\section{PENDAHULUAN}

Undang-Undang Republik Indonesia Nomor 44 Tahun 2009 tentang Rumah Sakit menyatakan bahwa rumah sakit adalah institusi pelayanan kesehatan yang menyelenggarakan pelayanan kesehatan perorangan secara paripurna yang menyediakan pelayanan rawat inap, rawat jalan, dan gawat darurat. Pelayanan obat di rumah sakit harus mengikuti standar pelayanan kefarmasian. ${ }^{1}$

Standar Pelayanan Kefarmasian di Rumah Sakit ditetapkan antara lain dalam upaya melindungi keselamatan pasien (patient safety) dari penggunaan obat yang tidak rasional. Pelayanan Kefarmasian di Rumah Sakit dilakukan oleh apoteker meliputi kegiatan pengelolaan obat dan pelayanan farmasi klinik. Pelayanan farmasi klinik merupakan pelayanan langsung yang diberikan apoteker kepada pasien dalam rangka meningkatkan outcome terapi dan meminimalkan risiko terjadinya efek samping obat, salah satunya adalah kegiatan rekonsiliasi obat. $^{2}$

Rekonsiliasi obat merupakan proses membandingkan antara instruksi pengobatan dokter dan obat yang telah didapatkan atau dibawa pasien sebelum masuk rawat inap. Rekonsiliasi obat dilakukan untuk mencegah terjadinya kesalahan obat (medication error) seperti obat tidak diberikan, duplikasi, kesalahan dosis atau interaksi obat. Tujuan dilakukannya rekonsiliasi obat yaitu memastikan informasi yang akurat tentang obat yang digunakan pasien, mengidentifikasi ketidak sesuaian akibat tidak terdokumentasinya instruksi dokter, dan mengidentifikasi ketidaksesuaian akibat tidak terbacanya instruksi dokter. ${ }^{3}$

Tahap proses rekonsiliasi obat yang dilakukan oleh apoteker di rumah sakit dimulai dari pengumpulan data yang dilakukan dengan mencatat dan memverifikasi obat yang sedang dan akan digunakan pasien, meliputi data karakteristik pasien, nama obat, dosis, frekuensi, rute pemberian, obat mulai diberikan, diganti, dilanjutkan dan dihentikan, riwayat alergi pasien serta efek samping obat yang pernah terjadi. Semua obat yang digunakan pasien tiga bulan terakhir, baik obat resep, obat bebas maupun herbal harus dilakukan proses rekonsiliasi obat. Tahap berikutnya dilakukan proses komparasi dengan membandingkan data obat yang pernah, sedang dan akan digunakan pasien. Discrepancy atau ketidak cocokan dapat terjadi apabila ada obat yang hilang, berbeda, ditambahkan atau diganti tanpa penjelasan/terdokumentasi pada rekam medik pasien. Ketidak cocokan ini dapat bersifat disengaja oleh dokter pada saat penulisan resep maupun tidak disengaja, yaitu dokter tidak tahu adanya perbedaan pada saat menuliskan resep. Setelah itu dilakukan konfirmasi kepada dokter, jika ditemukan ketidak sesuaian dokumen, dokter harus dihubungi kurang dari 24 jam. Tahap terakhir yaitu dilakukan komunikasi terhadap pasien dan/ atau keluarga pasien atau perawat mengenai perubahan terapi yang terjadi. Apoteker bertanggung jawab terhadap informasi obat yang diberikan. ${ }^{3}$

Data pada proses rekonsiliasi obat dicatat pada formulir rekonsiliasi obat. Kesimpulan rekonsiliasi obat yaitu: pengobatan tidak dilanjutkan, pengobatan dilanjutkan pada saat pasien masuk RS dengan perubahan regimen; dan diskrepansi pengobatan antara profil pasien sebelum rawat inap dan hasil wawancara pasien. Proses rekosiliasi obat merupakan tanggung jawab apoteker rumah sakit agar pengobatan pasien rawat inap dilakukan secara rasional. Namun demikian karena keterbatasan jumlah apoteker, maka rekonsiliasi obat juga dibantu oleh perawat dan dokter. ${ }^{3}$

Tujuan rekonsiliasi obat adalah melindungi pasien dari penggunaan obat tidak rasional. Penggunaan obat rasional adalah pasien mendapatkan pengobatan yang sesuai dengan kebutuhannya, untuk periode waktu yang adekuat dengan harga yang terjangkau. Kriteria pengunaan obat rasional adalah: tepat diagnosis, tepat 
indikasi, tepat obat, tepat dosis, tepat cara pemberian, tepat waktu pemberian, dan tepat lama pemberian. ${ }^{4}$

Sebuah penelitian rekam medis pasien rawat inap menemukan bahwa $85 \%$ rincian penggunaan obat terkini tidak konsisten atau tidak tepat. ${ }^{5}$ Sebanyak $74 \%$ kasus yang diteliti, pasien mendapatkan setidaknya satu obat yang tidak dalam pengawasan dokter atau dokter mengetahui akan tetapi tidak terlibat dalam regimen pengobatan. Data statistik diskrepansi pengobatan diperkirakan sekitar $60 \%$ medication error terjadi ketika pasien akan dirawat, pulang rawat atau pindah rawat. ${ }^{6}$ Diperkirakan $40 \%$ medication error berkaitan dengan kurangnya rekonsiliasi obat dan 20\% diantaranya dapat dihindari. ${ }^{7}$ Secara nasional Instalasi Gawat Darurat rumah sakit mempunyai beberapa upaya untuk menyediakan rekonsiliasi obat dan menemukan bahwa rekonsiliasi obat yang baik dapat menghasilkan dokumentasi pengobatan dan alergi pasien yang akurat serta mencegah medication error. ${ }^{8}$

Beberapa penelitian menunjuk-kan bahwa peran farmasi klinik dalam rekonsiliasi obat dapat menurunkan medication error, penurunan biaya terkait medication error dan menyediakan dokumentasi pengobatan pasien yang akurat. ${ }^{6}$ Penelitian menunjukkan bahwa sejumlah besar diskrepansi yang signifikan dapat dideteksi melalui proses rekonsiliasi obat. $^{3}$ Penelitian sebelumnya menemukan dari 481 masalah pengobatan yang terdeteksi, $83,8 \%$ diantaranya berpotensi mempunyai dampak klinis secara signifikan.

Komisi Akreditasi Rumah Sakit (KARS) juga mengatur kegiatan pengobatan pasien di dalam standar Manajemen dan Penggunaan Obat (MPO), yaitu kebijakan dan prosedur rekonsiliasi obat. ${ }^{9}$ Studi Benson dan Snow (2012) menunjukkan bahwa jika rekonsiliasi obat dilakukan pada saat pasien akan dirawat dan pulang rawat, maka diskrepansi pengobatan akan menurun. ${ }^{10}$ Apoteker harus mengkoordinasi, mengimplementasikan, mempertahankan dan memonitor proses rekonsiliasi obat yang efektif. ${ }^{11}$ Keterlibatan apoteker dalam rekonsiliasi obat secara signifikan meningkatkan keselamatan pasien (patient safety), menurunkan biaya akibat medication error dan efek obat yang tidak diharapkan. $^{11,12}$ Penelitian menunjukkan bahwa rekonsiliasi obat oleh apoteker di ruang emergensi dapat menurunkan kejadian medication error. ${ }^{13}$ Rekonsiliasi obat memerlukan validasi yang sistematik dan lengkap terhadap semua pengobatan pasien untuk memastikan bahwa obat harus ditambah atau mulai digunakan, diubah atau dihentikan. ${ }^{14}$

Kegiatan rekonsiliasi obat di Rumah Sakit Umum (RSU) X Bekasi yang merupakan salah satu RSU swasta kelas B terakreditasi KARS sudah dijalankan pada pasien rawat inap, khususnya pada pasien yang membawa obat sendiri. Proses rekonsiliasi obat dilakukan dengan cara wawancara pasien yang akan rawat inap oleh tenaga kesehatan, yaitu apoteker, perawat atau dokter. Hasil wawancara meliputi identitas pasien, dokter penanggung jawab pasien (DPJP), nama obat yang dibawa, dosis, frekuensi pemberian, lama pengobatan dan alasan minum obat dicatat pada formulir rekonsiliasi obat. Hasil wawancara selanjutnya disampaikan kepada DPJP untuk dibaca dan ditanda tangani, kemudian rekomendasi apakah obat dapat digunakan sebagai salah satu terapi atau tidak, berdasarkan kebutuhan terapi dan kondisi klinis pasien.

Obat yang direkomendasi DPJP kemudian disampaikan kepada tenaga kefarmasian beserta formulir rekonsiliasi obat untuk dinilai kondisinya apakah masih dapat digunakan atau tidak berdasarkan kondisi fisik obat dan tanggal kadaluarsa. Obat yang disetujui tenaga kefarmasian untuk digunakan pasien kemudian diserahkan kepada perawat. Obat yang tidak disetujui untuk digunakan, disimpan di nurse station (NS) agar tidak tercampur dengan terapi obat pasien yang akan digunakan dan 
dikembalikan kepada pasien pada saat pasien pulang. Semua data pada proses rekonsiliasi obat dicatat pada formulir rekonsiliasi obat

Masalah penelitian adalah adanya pengisian formulir rekonsiliasi obat yang tidak lengkap dan atau tidak dibaca dokter (tidak ada tanda tangan dokter), sehingga perlu dievaluasi apakah penggunaan obat pada pasien masih rasional. Tujuan penelitian adalah mengevaluasi hubungan antara kelengkapan pengisian formulir rekonsiliasi obat dan penggunaan obat rasional pada pasien rawat inap di RSU X Bekasi.

\section{METODE}

Rancangan penelitian menggunakan studi komparatif potong lintang. Populasi penelitian sebesar 466 formulir rekonsiliasi obat pada pasien rawat inap dewasa yang membawa obat sendiri di RSU X Bekasi periode bulan November 2015 sampai dengan April 2016. Kriteria inklusi sampel adalah formulir rekonsiliasi obat yang ada selama periode penelitian dan agnosis utama penyakitnya tercantum dalam pedoman klinis pengobatan pasien di RSU X Bekasi berupa Panduan Praktik Klinis atau Clinical Pathway. Kriteria eksklusi sampel adalah formulir rekonsiliasi obat yang tidak diisi. Pengambilan sampel secara total sampling terhadap formulir rekonsiliasi yang memenuhi kriteria inklusi, yaitu sebesar 189 formulir.

Variabel penelitian ini terdiri dari variabel bebas, yaitu kelengkapan pengisian formulir rekonsiliasi obat; variabel perancu berupa jenis tenaga pewawancara pasien, ada tidaknya tanda tangan DPJP, serta variabel terikat, yaitu penggunaan obat rasional (POR). Kriteria pengunaan obat rasional adalah: tepat diagnosis, tepat indikasi, tepat obat, tepat dosis, tepat cara pemberian, tepat waktu pemberian, dan tepat lama pemberian. ${ }^{4}$

Analisis data berupa distribusi frekuensi dan uji chi-square untuk menilai hubungan antara masing-masing variabel bebas, variabel perancu dan variabel terikat. ${ }^{15}$

\section{HASIL DAN PEMBAHASAN}

Karakteristik dan diagnosis utama pasien rekonsiliasi obat menunjukkan persentase terbesar pasien yang membawa obat sendiri termasuk kelompok umur dewasa (> 18-59 tahun), jenis kelamin perempuan (55\%), dan diagnosis utama penyakitnya Chronic Kidney Disease (CKD) 22,2\%, kemudian diare akut 12,2\% (Tabel 1). Diagnosis utama lain yang dapat ditelusuri kerasionalan penggunaan obatnya di RSU $\mathrm{X}$ antara lain abortus iminens, demam tifoid, Non ST-Elevation Myocardial Infarction (NSTEMI), tifoid, infeksi saluran kemih (ISK), post partum, demam dengue, post sectio caesaria (SC), appendicitis akut, asma bronkial, Dengue Haemorrhagic Fever (DHF) grade I dan II, DM tipe-2, hiperemesis gravidarum, kista endometriosis, mioma uteri, disentri amoeba, dispepsia tipe ulkus, fibroadenoma mama (FAM), hipoglikemia, pneumonia, sepsis dan STelevation myocardial infarction (STEMI).

Tabel 1. Karakteristik Pasien dan Diagnosis Utama 5 Besar Penyakit yang Dapat Ditelusuri Kerasionalan Penggunaan Obatnya di RSU X Bekasi,

\section{6}

\begin{tabular}{clcc} 
No & Diagnosis utama & Jumlah & \% \\
1 & CKD grade V on HD & 42 & 22,2 \\
2 & Diare Akut & 23 & 12,2 \\
3 & a. Dispepsia & 13 & 6,9 \\
& b. Stroke Non & 13 & 6,9 \\
& Hemoragik (SNH) & & 4,8 \\
4 & $\begin{array}{l}\text { a. Bronkopneumonia } \\
\text { b. Diare akut dehidrasi }\end{array}$ & 9 & 4,8 \\
& ringan-sedang & 9 & \\
5 & a. CHF & 8 & 4,2 \\
& b. DHF & 8 & 4,2 \\
\hline & Lain-lain & 64 & 33,9 \\
\hline & \multicolumn{1}{c}{ Jumlah } & 189 & 100 \\
\hline
\end{tabular}


Tabel 2. Deskripsi Pengisian Formulir Rekonsiliasi Obat pada Pasien Rawat Inap di RSU X Bekasi, 2016

\begin{tabular}{|c|c|c|c|}
\hline Parameter & Kriteria & Jumlah & $\%$ \\
\hline \multirow{2}{*}{$\begin{array}{l}\text { Kelengkapan } \\
\text { pengisian } \\
\text { formulir } \\
\text { rekonsiliasi obat }\end{array}$} & $\begin{array}{l}\text { tidak } \\
\text { lengkap }\end{array}$ & 133 & 70,4 \\
\hline & lengkap & 56 & 29,6 \\
\hline \multirow{2}{*}{$\begin{array}{l}\text { - Formulir } \\
\text { rekonsiliasi yg } \\
\text { diisi perawat } \\
\end{array}$} & $\begin{array}{l}\text { tidak } \\
\text { lengkap }\end{array}$ & 97 & 51,4 \\
\hline & lengkap & 92 & 48,6 \\
\hline \multirow{2}{*}{$\begin{array}{l}\text { - Formulir } \\
\text { rekonsiliasi yg } \\
\text { diisi apoteker }\end{array}$} & $\begin{array}{l}\text { tidak } \\
\text { lengkap }\end{array}$ & 26 & 13,8 \\
\hline & lengkap & 163 & 86,2 \\
\hline \multirow{2}{*}{$\begin{array}{l}\text { - Formulir } \\
\text { rekonsiliasi yg } \\
\text { diisi dokter }\end{array}$} & $\begin{array}{l}\text { tidak } \\
\text { lengkap }\end{array}$ & 120 & 63,5 \\
\hline & lengkap & 69 & 36,5 \\
\hline \multirow{2}{*}{$\begin{array}{l}\text { Identitas pasien } \\
\text { dan dokter }\end{array}$} & tidak ada & 0 & 0 \\
\hline & ada & 189 & 100 \\
\hline \multirow{2}{*}{$\begin{array}{l}\text { Nama dan } \\
\text { regimen dosis } \\
\text { obat pasien }\end{array}$} & tidak ada & 20 & 10,6 \\
\hline & ada & 169 & 89,4 \\
\hline \multirow{2}{*}{$\begin{array}{l}\text { Tanda tangan } \\
\text { apoteker }\end{array}$} & tidak ada & 23 & 12,2 \\
\hline & ada & 166 & 87,8 \\
\hline \multirow{2}{*}{$\begin{array}{l}\text { Tanda tangan } \\
\text { DPJP }\end{array}$} & tidak ada & 120 & 63,5 \\
\hline & ada & 69 & 36,5 \\
\hline \multirow{4}{*}{$\begin{array}{l}\text { Petugas } \\
\text { Interview pasien }\end{array}$} & dokter & 0 & 0 \\
\hline & perawat & 83 & 43,9 \\
\hline & apoteker & 106 & 56,1 \\
\hline & Total & 189 & 100 \\
\hline
\end{tabular}

Persentase terbesar pengisian formulir rekonsiliasi obat tidak lengkap 70,4\%, pengisian formulir rekonsiliasi obat kategori lengkap dilakukan oleh apoteker $86,2 \%$, ada identitas pasien dan nama dokter $100 \%$, ada nama dan regimen dosis obat yang dibawa pasien $89,4 \%$, ada tanda tangan apoteker $87,8 \%$, tidak ada tanda tangan DPJP 36,5\% dan pewawancara pasien rekonsiliasi adalah apoteker 56,1\% (Tabel 2).

Identitas pasien dan DPJP pada formulir rekonsiliasi pasien rawat inap yang membawa obat sendiri $100 \%$ karena rumah sakit menggunakan stiker barcode yang memuat identitas pasien dan DPJP untuk menjamin semua dokumen administrasi dan dokumen terapi pasien terisi lengkap dengan penulisan yang jelas. Kemungkinan penyebab nama dan regimen dosis obat yang dibawa pasien tidak ditulis lengkap karena obat tidak dibawa dalam klip plastik/etiket satu per satu obat tetapi 2 atau lebih obat dibawa dalam satu klip plastik/ etiket atau obat dibawa dalam satu kantong plastik kecil tanpa etiket obatnya.

Kemungkinan penyebab apoteker tidak membubuhkan nama dan tanda tangan pada formulir rekonsiliasi obat karena apoteker yang melakukan wawancara dan pemeriksaan kondisi fisik obat yang dibawa pasien sehingga hanya satu kali membubuhkan nama dan tanda tangan pada kolom petugas pewawancara.

Apoteker sebagai petugas pewawancara lebih banyak $(56,1 \%)$ daripada perawat $(43,9 \%)$ dalam kegiatan rekonsiliasi obat karena jumlah apoteker cukup banyak, 10 orang. Faktor lain yang menyebabkan banyaknya apoteker sebagai pewawancara karena menurut peraturan perundangan, rekonsiliasi obat dilakukan oleh apoteker yang selanjutnya disosialisasikan kepada dokter dan perawat agar ikut serta melaksanakannya. Lingkungan sekitar yang dapat menentukan keberhasilan program rekonsiliasi obat oleh apoteker adalah:profesi apoteker, dokter, pasien, dan sistem manajemen. ${ }^{16}$

Kemungkinan penyebab nama dan regimen dosis obat yang dibawa pasien tidak ditulis lengkap karena obat tidak dibawa dalam klip plastik/etiket satu per satu obat tetapi 2 atau lebih obat dibawa dalam satu klip plastik/ etiket atau obat dibawa dalam satu kantong plastik kecil tanpa etiket obatnya.

Kemungkinan penyebab apoteker tidak membubuhkan nama dan tanda tangan pada formulir rekonsiliasi obat karena apoteker yang melakukan wawancara dan pemeriksaan kondisi fisik obat yang dibawa pasien sehingga hanya satu kali membubuhkan nama dan tanda tangan pada kolom petugas pewawancara.

Apoteker sebagai petugas pewawancara lebih banyak $(56,1 \%)$ daripada perawat $(43,9 \%)$ dalam kegiatan rekonsiliasi obat karena jumlah apoteker cukup banyak, 10 orang. Faktor lain yang menyebabkan banyaknya apoteker sebagai pewawancara karena menurut 
peraturan perundangan, rekonsiliasi obat dilakukan oleh apoteker yang selanjutnya disosialisasikan kepada dokter dan perawat agar ikut serta melaksanakannya. Lingkungan sekitar yang dapat menentukan keberhasilan program rekonsiliasi obat oleh apoteker adalah:profesi apoteker, dokter, pasien, dan sistem manajemen. ${ }^{16}$

Deskripsi penggunaan obat rasional di RSU X Bekasi menunjukkan persentase terbesar penggunaan obat: tepat diagnosis dan tepat indikasi masing-masing 53,4\%, tepat pemilihan obat $33,9 \%$, tepat dosis $8,5 \%$, tepat cara pemberian $37,6 \%$, tepat interval waktu pemberian $13,8 \%$ dan tepat lama pemberian $14,8 \%$ (Tabel 3). Penggunaan obat rasional berdasarkan pedoman klinis yang memenuhi kriteria 7 tepat tersebut hanya $7,9 \%$.

Tabel 3. Penggunaan Obat Rasional pada Pasien Rekonsiliasi Obat di RSU X Bekasi, 2016

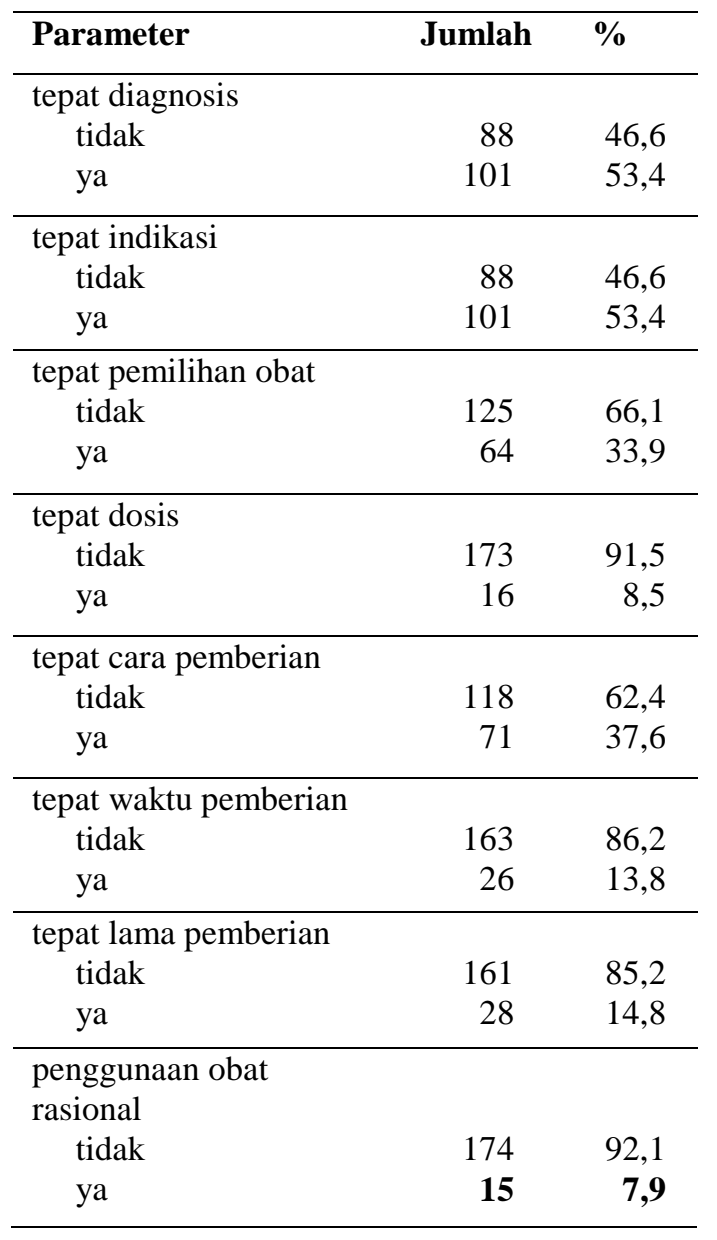

Penggunaan obat tidak rasional dapat berdampak pada mutu pengobatan, biaya pengobatan, kemungkinan terjadi efek samping dan efek lain yang tidak diharapkan, mutu ketersediaan obat dan dampak psikososial pasien. ${ }^{17}$ Sosialisasi kembali pedoman klinis rumah sakit baik Pedoman Praktek Klinis maupun clinical pathway diharapkan dapat meningkatkan penggunaan obat rasional di RSU X Bekasi.

Analisis ini juga menunjukkan bahwa jumlah penggunaan obat tidak rasional lebih besar dibandingkan dengan jumlah penggunaan obat rasional baik pada wawancara yang dilakukan oleh perawat maupun oleh apoteker masing-masing berjumlah 63,9\% (53 formulir) dan $64,2 \% \quad$ (68 formulir). Penyebab penggunaan obat tidak rasional karena validasi terhadap rekonsiliasi pengobatan tidak dilakukan secara sistematik dan lengkap terhadap semua pengobatan pasien sehingga pemastian penambahan, perubahan atau penghentian obat dan perbaharuan daftar obat pasien tidak dapat dilakukan secara optimal. ${ }^{18}$

Peran apoteker dalam kunjungan ke bangsal pasien rawat inap dan pengkajian resep yang menurunkan peresepan obat yang tidak sesuai selama pasien rawat inap harus lebih optimal agar keselamatan pengobatan selama perawatan pasien khususnya dan pada saat transisi dari rumah sakit pulang ke rumah dapat ditingkatkan. ${ }^{19}$

Hubungan antara kelengkapan pengisian formulir rekonsiliasi obat dan penggunaan obat rasional menunjukkan hubungan antara kelengkapan pengisian formulir rekonsiliasi pasien yang membawa obat sendiri dan penggunaan obat rasional pada pasien rawat inap secara statistik tidak bermakna ( $p$ value $=$ 0,076 atau >0,05). 


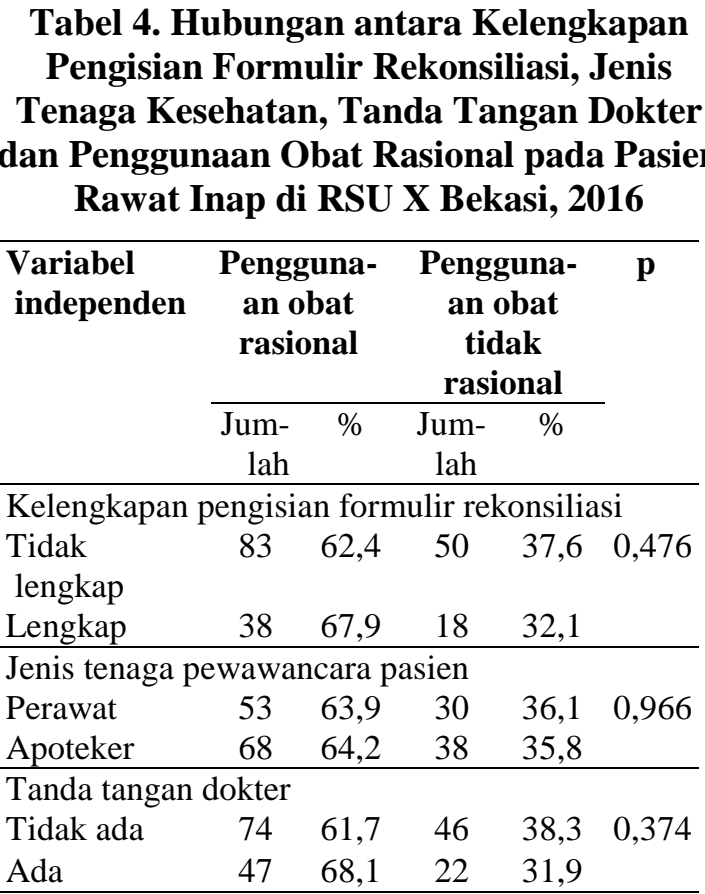

Hubungan antara jenis tenaga kesehatan pewawancara pasien dan penggunaan obat rasional pada pasien rawat inap secara statistik tidak bermakna ( $p$ value $=0,966$ atau $>0,05)$. Selanjutnya, hubungan antara ada tidaknya tanda tangan dokter pada formulir rekonsiliasi dan penggunaan obat rasional pada pasien rawat inap secara statistik tidak bermakna ( $p$ value $=0,374$ atau $>0,05$ ) (Tabel 4).

Hubungan antara ketiga variabel rekonsiliasi dan penggunaan obat rasional pasien rawat inap tidak signifikan mungkin disebabkan Pedoman Praktek Klinis dan clinical pathway. ${ }^{20}$ Pedoman Praktek Klinis dan clinical pathway RSU X Bekasi untuk hampir semua diagnosa penyakit sangat sempit pilihan terapi obatnya, yaitu sangat spesifik sampai ke nama generik dan bahkan nama dagang. Pada pedoman terapi RS lain pilihan terapi obatnya hanya sampai golongan obat sehingga sampel yang memenuhi kriteria penggunaan obat rasional berdasarkan pedoman terapi lain lebih banyak dibandingkan dengan Pedoman Praktek Klinis/clinical pathway RSU X Bekasi.

Pedoman praktek klinik sebagai aturan peresepan dan rekonsiliasi obat sebagai informasi obat, merupakan dua hal dari enam faktor yang mempengaruhi pola peresepan obat rasional yaitu, pengaturan obat (regulasi), pelatihan, pengaruh industri farmasi (iklan, insentif, dll.), informasi obat, sistem asuransi, dan hubungan dokter-pasien. ${ }^{21}$

\section{KESIMPULAN}

Persentase terbesar pengisian formulir rekonsiliasi pasien yang membawa obat sendiri tidak lengkap $(70,4 \%)$, dilakukan oleh apoteker $(56,1 \%)$ dan tidak ditanda tangani dokter $(63,5 \%)$. Persentase penggunaan obat rasional sebesar 7,9\%, Tidak ada hubungan antara kelengkapan pengisian formulir rekonsiliasi obat, kualifikasi tenaga kesehatan pewawancara pasien, ada/ tidaknya tanda tangan dokter dan penggunaan obat rasional pada pasien rawat inap di RSU X Bekasi ( $p>0,05)$.

\section{SARAN}

Perlu dilakukan revisi formulir rekonsiliasi pasien yang membawa obat sendiri berupa penambahan kolom yang menunjukkan jika ada kondisi obat tetap diberikan berdasarkan persetujuan dan sepengetahuan DPJP berikut alasannya. Pedoman Praktik Klinis dan Clinical Pathway di RSU X Bekasi disosialisasikan kembali kepada dokter supaya dapat memberikan terapi pengobatan sesuai pedoman. Selanjutnya diperlukan pelatihan seluruh petugas kesehatan di RSU X Bekasi terutama dokter, perawat dan apoteker mengenai rekonsiliasi pasien yang membawa obat sendiri agar semua pihak lebih serius terhadap riwayat pengobatan pasien.

\section{UCAPAN TERIMA KASIH}

Ucapan terima kasih disampaikan kepada civitas akademi program magister Fakultas Farmasi UI dan Direksi beserta staf RSU X di Kota Bekasi yang telah memberikan izin lokasi penelitian. 


\section{DAFTAR RUJUKAN}

1. Republik Indonesia. Undang-Undang Republik Indonesia Nomor 44 Tahun 2009 Tentang Rumah Sakit.

2. Republik Indonesia. Peraturan Menteri Kesehatan RI Nomor 72 Tahun 2016 tentang Standar Pelayanan Kefarmasian di Rumah Sakit.

3. Mueller SK, Sponsler KC, Kripalani S, Scnipper JL. Hospital-based medication reconciliation practices. Arch Intern Med. 2012;172(7):1057-69

4. World Health Organization. The Rational use of drugs: Report of the Conference of Experts.1985

5. Pronovost P, Weast B, Schwarz M, Wyskiel R M, Prow D, Milanovich SN, et. al. Medication reconciliation: a practical tool to reduce the risk of medication errors. Journal of critical care. 2003;18(4):201-5.

6. Rozich JD, Resar RK. Medication safety: One organization's approach to the challenge. JCOM. 2001;8(10):27- 34

7. Okere AN, Gessert C, Renier C, Swanoski M. Effects of medication reconciliation service provided by student pharmacists in a tertiary care emergency department. Innovations in pharmacy;2013;4:1-9.

8. Steeb D, Webster L. Improving care transitions: optimizing medication reconciliation. J Am Pharm Assoc. 2012;52(4):43-52.

9. Komisi Akreditasi Rumah Sakit. Instrumen Akreditasi Rumah Sakit: Standar Akreditasi Versi 2012. 2012; (12):142-165.

10. Benson, J M, Snow G. Impact of medication reconciliation on medication error rates in community hospital cardiac care units. Hospital Pharmacy. 2012;47(12):927-32.

11. Super TM, Phillips SW, Coffey RP, Patterson S. Impact of pharmacist facilitated discharge medication reconciliation. Pharmacy. 2014;2(3):22230 .

12. Strunk LB, Matson AW, Steinke D. Impact of a Pharmacist on medication reconciliation on patient admission to a veterans affairs medical center. Hospital Pharmacy. 2008; 43(8):643-49.
13. Midlov P, Bahrani L, Seyfali M, Hoglund P, Rickhag E, Eriksson T. The effect of medication reconciliation in elderly patients at hospital discharge. International journal of clinical pharmacy. 2012;34(1):113-19.

14. Jansen PAF, Brouwers JRBJ. Clinical pharmacology in old persons. Scientifica. 2012;(6):1-17.

15. Supardi S, Surahman. Metodologi penelitian untuk mahasiswa farmasi. Jakarta: Trans Info Media; 2014.

16. Kennelty KA, Chewning B, Wise M, Kind A, Roberts T, Kreling D. Barriers and facilitators of medication reconciliation processes for recently discharged patients from community pharmacists' perspectives. Research in Social and Administrative Pharmacy. 2015;11(4):517-30.

17. Kementerian Kesehatan Republik Indonesia. Kurikulum Pelatihan Penggunaan Obat Rasional (POR). Jakarta; 2011.

18. Catalonia Ministry of Health. Rational drug use. Medication management in the complex chronic patient: reconciliation, revision, deprescription and adherence. 2014;(4):4-22

19. Leguelinel-Blache G, Arnaud F, Bouvet S, Dubois F, Castelli C, RouxMarson, $\mathrm{C}$, et al. Impact of admission medication reconciliation performed by clinical pharmacists on medication safety. European Journal of Internal Medicine. 2014;25(9):808-14.

20. Brahma D, Marak M, Wahlang J. Rational use of drugs and irrational drug combinations. The Internet Journal of Pharmacology. 2012;10(1): $1-5$.

21. Scordo KA. Teaching students about the WHO guide to good prescribing. The Nurse Practitioner. 2014;39(3):51-4. 